\title{
HUMAN PAPILLOMA VIRUS: A POSSIBLE CULPRIT IN CHRONIC RHINOSINUSITIS WITH NASAL POLYPOSIS
}

*Seddlik Abd El Salam Tawfik, *Ahmed Ali Ibrahim, Remon Rafat Kalsa Bazak, **Samar Nabil El Achy, *Mostafa Nasr Abdel Tawab Atia

\section{Introduction}

*Department of Otorhinolaryngology,** Department of Pathology, Faculty of Medicine, Alexandria University

Chronic rhinosinusitis with nasal polyposis (CRSwNP) comprises heterogeneous clinical pictures and can be categorized into two types: eosinophilic type and noneosinophilic one. The allergy role in the pathogenesis of CRSwNP is still debatable. Tcell-mediated immune reaction may play a significant role in eosinophilic CRSwNP. The count of eosinophils has been positively correlated with the count of mast cells and the remaining inflammatory cells as a whole. Human papillomavirus (HPV) was the remaining inflammatory cells as a whole. Human papillomavirus (HPV) was
strongly accused in the development of inverted papilloma, but it has not been searched adequately as the culprit for the development of CRSwNP.

\section{Aim of the work}

The present research aimed to detect HPV in patients with CRSwNP, find any relation between HPV and tissue eosinophilia.

\section{Patients and Methods}

The study had been conducted on a total number of 90 patients. All patients are asked to withhold steroids and antihistamines four weeks before taking samples and excluded for mucociliary dysfunction or immunodeficiency. A computec tomography (CT) scan on nasal and paranasal sinuses had been dictated before taking sample for all patients. A blood sample for detection of blood eosinophili in both diseased and control goups. Histopthologida specimens was done for tissue eosinophilic count and percentage among other Results

Table (2): Relation between Blood eosinophils count of total leukocytic count (1000) with Tissue eosinophilic average count over $10 \mathrm{HPF}(n=43)$
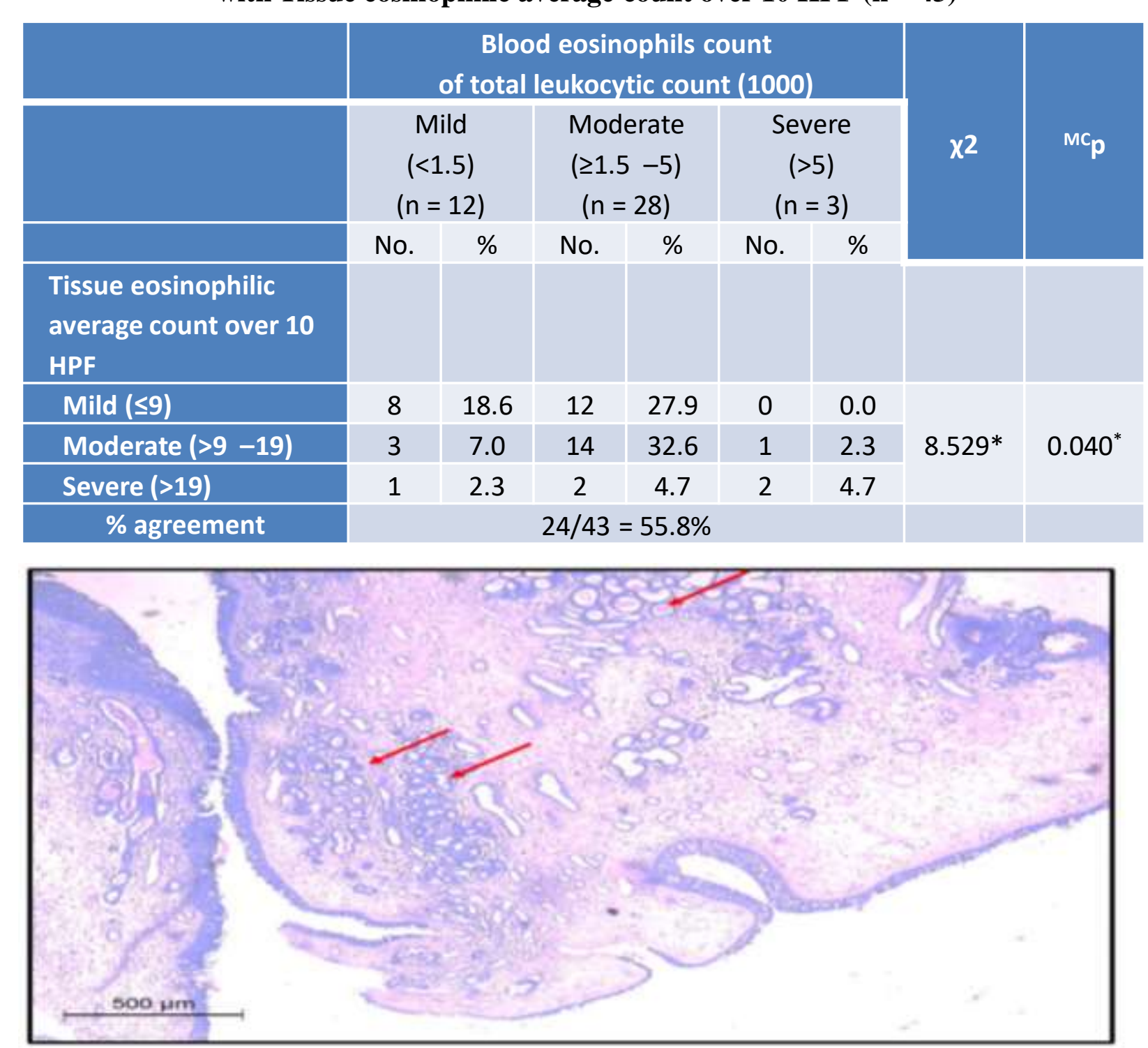

Figure (1): A photomicrograph showing a low power view of nasal polypi lined by pseudostratified columnar epithelium with moderate inflammatory infiltrates in an oedematous fibrous stroma, as well as mucus gland hyperplasia (arrows). (H\&E Stain)

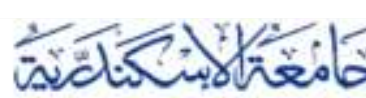
ALEXANDRIA

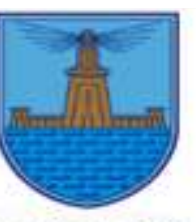

2021 Alexandria Faculty of Medicine CC-BY-NC

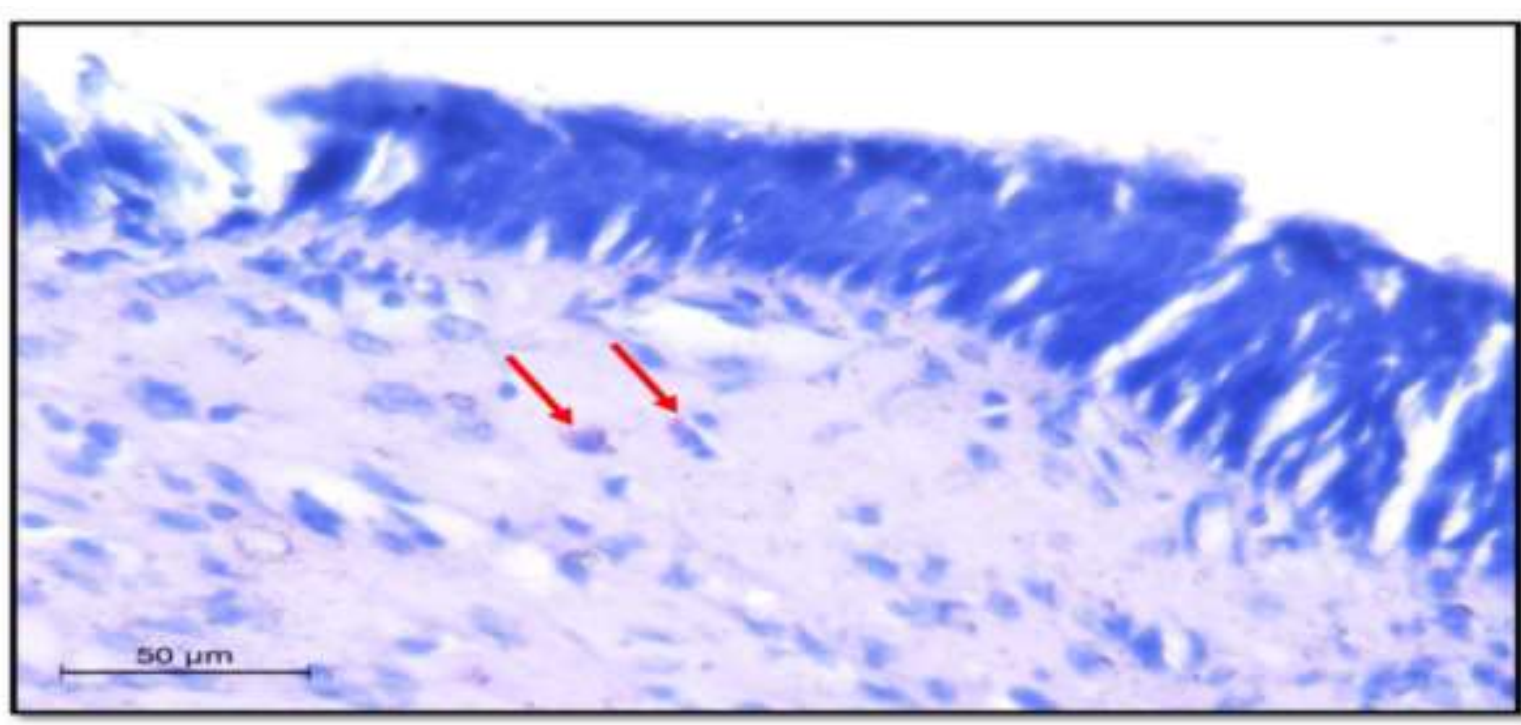

Figure (2): $\quad$ A photomicrograph showing a nasal polyp lined by pseudostratified columnar epitheliun with fow ing A A

\section{Conclusion}

PCR did not detect any of the 28 genotypes of HPV in neither polyps of patients with CRSwNP nor the nasal mucosa of normal controls, rendering the pathogenic role of HPV in CRSwNP unlikely. Total eosinophilic count within the polyps and their percentage relative to the other inflammatory cells showed a weak positive correlation with the blood eosinophilia. Single site sampling to study tissue eosinophilia is not accurate, as tissue eosinophils have a variable distribution in nasal polyps and within different parts of the each polyp

\section{REFERENCES}

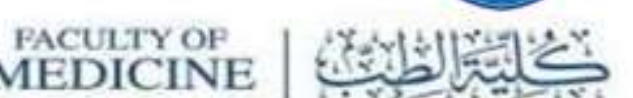

1. Fokkens WJ, Lund VJ, Hopkins C, Hellings PW, Kern R, Reitsma S, et al. European Position Paper on Rhinosinusitis and Nasal Polyps 2020. Rhinology 2020; 58(Suppl S29):1-464.

Kanda A, Yun Y, Bui DV, Nguyen LM, Kobayashi Y, Suzuki K, et al. The multiple function and subpopulations of eosinoph

3. Ioannidis D, Lachanas VA, Florou Z, Bizakis JG, Petinaki E, Skoulakis CE. Herpes viruses and human papilloma virus in nasal polyposis and controls. Braz J Otorhinolaryngol 2015; 81(6):658-62. 